\title{
Sprinting for creative economy growth - a case study of a business planning and rapid prototyping toolkit for the Brazilian creative economy sector
}

\author{
Richard Tomlins ${ }^{1, *}$, Helen Cuthill ${ }^{1}$, Alan Richards ${ }^{1}$, Arun Sukumar ${ }^{1}$, and Oksana Malynka ${ }^{2}$ \\ ${ }^{1}$ Coventry University, England \\ ${ }^{2}$ Ivano-Frankivsk National Technical University of Oil and Gas, Ukraine
}

\begin{abstract}
This article reflects on the development of a creative economy training product and toolkit developed by Coventry University with SEBRAE (the Brasilian Micro and Small Business Support Service) and funded by British Council. It was devised following two weeks creative economy scoping visits in autumn 2017 in Brasil. The scoping visits identified the need for a fun and "disruptive" business planning experience leading to rapid prototyping which would allow new creative economy ideas to be brought to market at low development cost - "Sprint". A one day micro Sprint was tested in four locations in Brazil to excellent feedback in late 2017. The client subsequently requested a three day version of the methodology to invest more time in the cultural change of the creative entrepreneur and the development of an associated toolkit. However, this Sprint has subsequently also been rolled out in a super condensed 3 hour version piloting in 2019 and 2020 in Ukraine through British Council Creative Spark programmes. The toolkit offers skills and techniques to train creative entrepreneurs and their mentors in enabling the growth of the creative economy in their communities. This paper predominantly focuses on the implementation of the client commissioned three day Sprint.
\end{abstract}

\section{Introduction}

"Every idea is a product of thinking and every product is the manifestation of idea naked in a thinker's mind" [1].

In this era of extraordinary change and globalisation, many acknowledge that creativity and innovation are now driving the new economy. Creativity has become a powerful source of competitive advantage and a driving force for progress. Organisations and even economic regions that embrace creativity generate significantly higher revenue and provide greater stability into the future [2].

The modern form of globalisation determines a new plane in which cultural practices interact with creativity and innovation on a global scale shaping in such a way a new sector of the economy - creative industries. This encompasses economic activities concerning the generation, exploitation, transformation, dissemination and commercialisation of information and knowledge and bringing significant economic and social impacts (for example driving sustainable development and inclusive job opportunities). Therefore, the creative industries are converted into a stabilising element of country's competitiveness [3].

Developed countries around the world have now transitioned into functioning within a knowledge economy where information and knowledge are important drivers of economic growth. As we navigate this move to a post-industrial knowledge economy, from an economy solely based on the production of goods to an economy significantly fuelled by ideas and innovation, the role of creativity in shaping and driving that growth can no longer be ignored. The creative economy can also be seen as revitalising manufacturing through the interaction of creatives with advanced manufacturing [4].

If we are to thrive in business we must be creative. Business is a creative activity. Success in entrepreneurship today demands constant innovation. [5]. Generating fresh solutions to problems, and the ability to invent new products or services for a changing market, are part of the intellectual capital that gives an organisation its long-run sustainable competitive advantage including engaging with Industry 4.0 [6].

This teaching case study provides an outline of how creative entrepreneurs and sector consultants can run a Sprint with creative economy consultants and with creative entrepreneurs. However, more widely it outlines an adapted "Rapid Prototyping" tool that can be used across sectors to establish a "Minimum Viable Product" [7].

Funded by the British Council and developed by Coventry University in conjunction with SEBRAE in Brasil, this three day Sprint approach and toolkit results from two weeks of creative economy scoping visits. These were conducted by Dr Richard Tomlins in Alagoas, Pernambuco, Minas Gerais and Rio de Janeiro

* Corresponding author: aa3252@coventry.ac.uk 
in Brasil in autumn 2017. The funding sought to lever expertise and leadership from the UK Creative Economy sector to the benefit of its counterpart in Brasil. Throughout 2019 we began rolling out the same approach as part of a pack of playful methodologies in Ivano-Frankivsk, Ukraine also funded by the British Council. This work will continue in 2020.

We outline below the overall context of the creative economy for the project and the British Council's overall and Brasil specific approach before outlining the component parts of the published version and a further condensed version.

\section{Context}

"The future is already here. It's just not evenly distributed yet." [8]

Creativity can be described as "an inexhaustible resource based mainly on the ideas and cultural characteristics rather than on the physical capita". The sources of creativity include talent, personal emotions, knowledge, intuition, imagination, the ability to produce new ideas, and to solve problems as well as the cultural assets of each society (traditions, cultural values and heritage) [3].

New knowledge and creative skills which lead to disruptive innovation and are the most powerful drivers of economic growth in the modern economy, are formed at the intersection of fields and cultures. Over the past few years, more and more innovation spaces, ideation hubs, incubator labs and coworking spaces were designed to inspire people from diverse cultures and fields of expertise to interact with each other and foster creativity. The first who recognised the significance of such spaces were global companies like Google, Twitter and Facebook which provided their offices and campuses with inspiring creative infrastructure for their employee. Governmental structures at all levels, industry corporations, educational establishments and research institutions have started providing similar environments for the general public [9].

The modern creative environment is rich in different innovative forms of drivers of entrepreneurship like clusters, hubs, coworkings, business-incubators, accelerators, which became the strengthening power for regional competitiveness and economic growth. Thus, idea generation needs a combination of skills, knowledge, talented individuals, and above all a good inspiring creative environment [10].

The creative economy has boomed in the UK over the last decade in economic terms stimulating increasing policy and academic inputs and increasing interest in the way in which creatives and innovators add value not only through a "badged" set of industries but also as part of the wider economy.

The British Council has been and is part of this process, in addition to providing the funding for our Sprint. A charity but also a public body it has as part of its remit to promote cultural relationships and understanding [11]. It sees the creative economy as not only an economic instrument but a path to greater wellbeing and community cohesion [12].

SEBRAE our original Brasilian funding partner also recognises the importance of this sector with specialist resources targeted at its growth [13]. In Brasil the Minister of Culture has stated that the cultural and creative activities already represent $2.6 \%$ of the Brasilian GDP, generate one million direct jobs and encompass more than 200 thousand companies and institutions. Nevertheless, "there is a great potential for growth and this involves the internationalization of our talents and of our valuable cultural production" [14]. As our work moves to Ukraine we are seeing similar drivers and interest.

Despite this enthusiasm it is not always clear if we are talking about the same thing as creative economy. In Brasil different states clearly had different creative economy priorities and potentially definitions.

Does this matter?

It certainly became material to us in project design as we "tore up" the project plan from the winning bid which would have deployed subject experts to deliver specialist expertise in favour of the more generic and we felt far reaching rapid business prototyping.

\section{Project scope}

The Invitation to Tender for this project was designed to expand British Council Brasil's creative economy activities beyond pilot activities in São Paulo.

It commissioned UK creative economy "expertise" as a catalyst for growth in its Brasilian counter-part and for wider cultural exchange with the UK. This reflected a commitment from all parties to co-design and coproduction to deliver expertise and drive inclusive change.

The target outcomes were to:

- generate business and technological development.

- carry out capacity building targeting the creative economy industries.

- reduce economic inequalities among young people living in remote and low-income areas.

- integrate knowledge of the creative economy culture into SEBRAE's networks and programmes supporting;

- vulnerable populations,

- promoting economic opportunities

- social development in local contexts.

These targets sat within an overall aim to provide participants with expertise and confidence, enabling them to train and mentor creative entrepreneurs (or potential creative entrepreneurs) from marginalised neighbourhoods.

\section{Why Sprint?}

Our winning British Council tender proposed specialist creative economy support based around the specific creative expertise that each project location demanded. We also proposed to work with delegates to identify the social value [15] that they not only produced but also 
could produce to future proof them against future budget cuts.

However, our scoping visit identified that we could add greatest project value through using Sprint as a creative, fun and time focused rapid prototyping tool. This would offer particular benefits to creative entrepreneurs who found aspects of traditional business planning inaccessible.

The social value element was retained as a thread through different sections of the Sprint toolkit to address the specific needs of "vulnerable populations" and the inequalities that they face.

Sprint sits firmly in the design thinking pedagogy and whilst describing itself as a "greatest hits" [16] of business thinking we see it as a commodification and branding of design thinking in a particularly accessible and intuitive way. It is driven by empathy and (re)iteration although we were keen in delivery to ensure that empathy was not pejorative in the context of our emphasis on co-design and co-production.

We felt that we could offer an innovative, fun, compressed and productively disruptive business planning experience through Sprint playfully meeting the needs of creative entrepreneurs. This would build on Coventry University's work developing the Google Ventures Sprint concept including micro Sprints to produce rapid prototypes of products and services with minimum resource investment. The discipline of time constraints and quick decision making are crucial to the process of cultural change to achieve the prototype forcing people to bring an idea to fruition.

Google Ventures wrote Sprint as a 5 day workshop, nevertheless in our work we have experimented and successfully delivered a one day Sprint programme in Brasil and subsequently 3 hour versions in São Paulo and 2 hour versions in Ivano-Frankivsk. However, the three day Sprint programme remained the British Council's preferred instrument for achieving a significant step change for the creative entrepreneurs.

\section{Running the workshop}

\section{Numbers}

Google Ventures recommends no more than seven people in each group, although you might have an extra facilitator. The process works on group creative energy. This could be an existing work team or a group of different creative entrepreneurs.

\section{Time}

The Sprint time needs to be blocked in the calendar. If team members can't make this commitment then they're not ready to Sprint. It will destroy the energy if participants drop "in and out" of the session. Facilitating the Sprint also means minimising distractions. No laptops, phones, or iPads allowed, other than the odd occasion they need to be used to look something up as part of the Sprint. The team needs to focus rather then multi-task.

\section{Who should be on the Sprint team?}

\section{The facilitator}

You need a facilitator for a Sprint to challenge assumptions, see possibilities and turn problems into opportunities. They need to keep the pace moving otherwise the Sprint will not work! Slow decisions sap energy and threaten the timetable and most importantly the momentum of the work. The facilitator will need to build in regular breaks to the programme and have the flexibility to end sessions early if attendees are becoming tired. For lunch, eat together if you can. We had our best results when the team bonded over lunch and took the energy of the morning session into the afternoon.

\section{The decider}

A "decider" is also needed as part of each work group, with the authority to decide what will happen going forward in the creative enterprise taking part in the Sprint. If you have à group of different creative entrepreneurs then you still need a decider agreed by the group to make decisions to keep Sprint moving with the speed that the process requires,

\section{Drawing}

Participants are going to do a lot of drawing as part of the Sprint and if you're the facilitator you are going to have to make sure that people in the majority of cases draw rather than write

\section{Teaching notes (a three day Sprint)}

\section{Day one - from general policy and market context to the Big Opportunity}

We began by outlining Sprint as a rapid prototyping tool in contrast with the wider and more strategic focus of tools such as Business Model Canvas (BMC).

Group introductions led into an ice breaker and ground rules - "no distractions!!" - before groups were asked to decide on their "decider".

We drew on our own scoping visit, but also the local knowledge of the creative economy consultants and attendees to outline overall market opportunities locally, nationally and globally for the creative entrepreneurs.

The second part of day one allowed creative entrepreneurs to define their Big Opportunity for addressing that challenge. Delegates had to frame this opportunity in broad terms to provide a range of possibilities any one of which could be prototyped by the end of day $3 \ldots$ and they had to draw the opportunity.

We were careful not to let the group wait too long to start drawing. There's no need to practice the drawing or sketch it in pencil first, in fact this becomes counterproductive by making the Sprint process too cautious or over-refined before it has had the change to be properly outlined! Similarly we wanted a picture at this stage that 
conveyed an idea rather than an artistic masterpiece to be perfected.

We were careful to encourage all the group to be involved in the drawing process and to avoid some of the group opting out of the process. We encouraged different members of the group to work on different parts of the flip chart or identify how something can be drawn.

This drawing from some of our Recife Sprint delegates captured their desire to ensure that the local gastronomy offer could touch all of our senses - that the consumer would be immersed in its authenticity and significance.

The richness of the Sprint was demonstrated by the extensive range of prototypes from the above idea - from apps to artificial intelligence and immersive "real-time" experiences (figure 1).

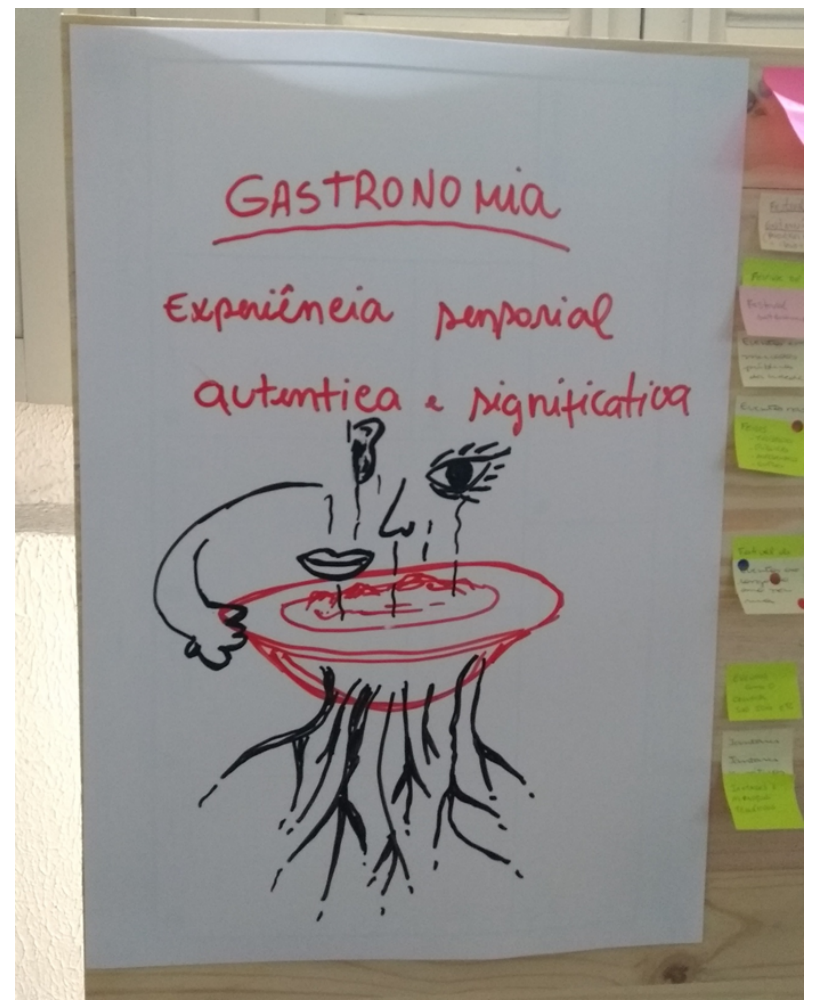

Fig. 1. Drawing from Recife Sprint delegates.

\section{Identifying the target customer market}

We got the group to pin their flip chart to the wall and asked the "decider" to present the opportunity to the rest of the room to make sure everyone was on the same page.

Finally for day one we got delegates to identify the three critical success factors for the prototype as a reference point for the final stage of day 3 .

Day two required the creative entrepreneurs to consider, identify and of course draw their target customer market on a sheet of flip chart. We asked whether this was existing customers, potential customers, or both?

In our meetings with Samba Schools in Rio and Recife we discussed ways of widening their target market beyond the consumers of the Samba or Carnival event itself to wider music consumers. A new customer base related to their existing customer base.

We asked would the customer target market benefit from being segmented or were there synergies? For example, Instituto Cultural Polen's digital offer includes working with young people from favelas in Rio de Janeiro for example through its CriaAtivo Film School project. However, its wider digital work has drawn parents into working in the same space as their children increasing project footprint.

The facilitator had an important guiding role at this point for the Sprint group. We wanted Sprinters to focus on an identifiable group of potential customers, however for the market to remain viable in size. They had to consider how far to segment the target market. We asked was the target market local, regional, national or international? For example, we saw the way in which SEBRAE were working with different handicraft producers to increase their offer and visibility to collectors and international markets in our visits to Brazil.

Might delegates' target market be another business? In Alagoas one embroidery association Mimos de Dona Peró had identified one local artisan handicraft centre as a customer. Embroidered pieces were being incorporated into the clay master maker pieces and adding value.

Might the target market be potential investors and/or Government? In Minas Gerais, the State Government was interested in working with the emergent film industry to grow the Audio Visual sector.

Sprinters should end with something like our visitor to Recife as a visual reference point for the actions that they need to take (figure 2).

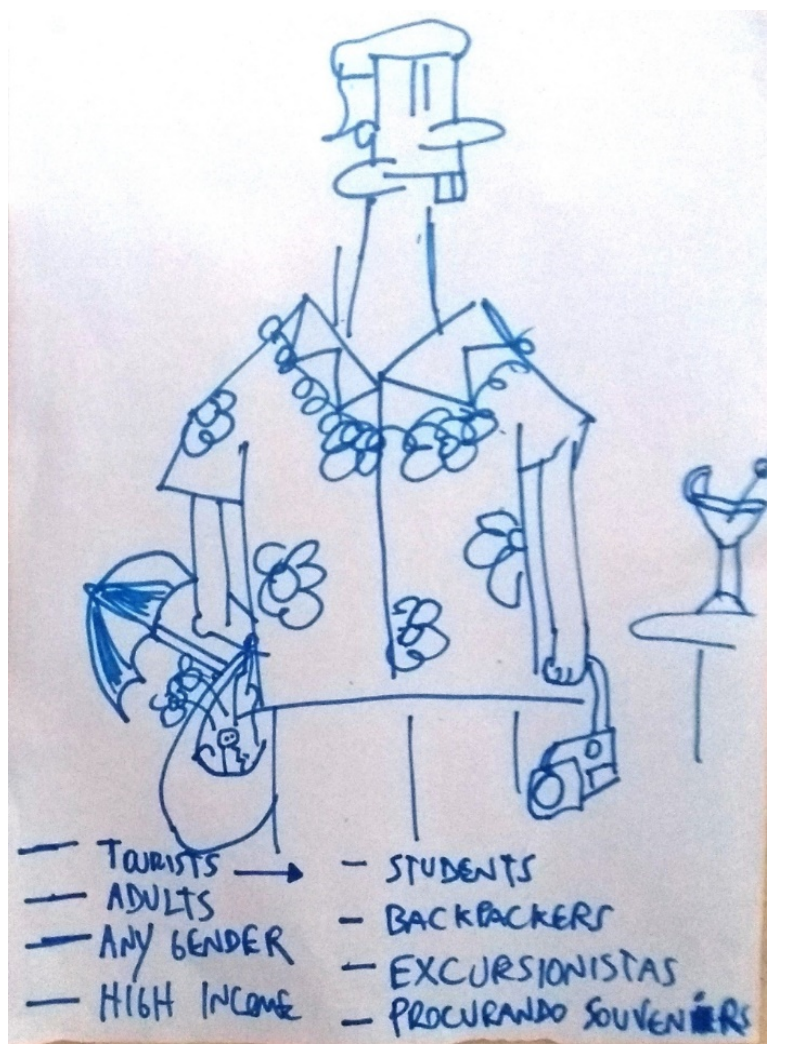

Fig. 2. Drawing from Recife Sprint delegates. 
We got delegates to pin the flip chart drawing to the wall near to, but not next to the key idea or challenge. They had to fill in the gap next between this drawing and the Big Opportunity with more drawings showing how they were going to achieve that opportunity!

The second half of day two was delegates' (only!) chance to write rather than draw over the three days.

In fact, by the end of the afternoon they identified the service or product that they would prototype on day 3 to realise their Big Opportunity. They did this through a "how might we" exercise, writing on large post it notes as many ideas as they could think of for reaching their target market.

We made them to do it quickly to produce a rapid cascade of ideas, written with a marker pen to ensure that they didn't overload the "post it" with too much detail. We got the delegates to do the task individually and in silence! We didn't want "group think", we wanted a cascade of ideas.

Delegates were asked to stick the "post it" notes on a sheet of flip chart or just the wall next to the key challenge flip chart.

The more ideas and post - its the better. At this stage we asked the delegates to organise all the HMW notes into themes so that it was easier to focus on the merits of each idea, whilst emphasizing that they shouldn't worry about perfecting the themes, the exercise was a means to an end not to be graded!

Next we got the delegates to prioritise the most useful HMWs by voting on them - in silence - with sticky dots. At this stage it's the HMWs that they think have the best chance of realising the Big Opportunity that should get the votes.

Why silence?

We were again trying to avoid "group-think" and ensure that the quieter members of the group were "heard". Delegates got five dots each, although they could only put one on any one HMW post it note including any of their own ideas! We hurried the group along to get dots on post it notes to avoid "paralysis by analysis". Where there was a tie in the "dot voting" then the "decider" made the decision on which idea to prototype to keep the prototype moving. The HMW idea with the most dots was the one that the group went on to prototype.

The remainder of the HMWs become a portfolio that Sprinters could return to and test at a future time or even within the three day Sprint if the timetable allowed.

\section{Day three from storyboarding to prototyping}

The morning of day three was drawing out as a storyboard how to put the chosen HMW idea into practice. This was delegates' guide to the key features that they needed to include in the prototype later that day.

The storyboard gave the creative entrepreneurs time to consider and specify what the prototype product or service would look like.

To achieve this Sprinters individually brainstormed how they could realise the chosen HMW idea from day two. This was another silent task to avoid "group think" and we used the "crazy eights" technique to achieve this goal. Blank paper and marker pens were handed out to all participants. This involved asking everyone to fold a sheet of paper in half 4 times. We then gave 30 minutes total for each delegate to draw eight rough sketches (one per folded panel) of how they might realise the group's chosen HMW idea. Throughout the exercise we continued to remind people of the time and made sure that it was clear which sketch they should be on.

When time was up we got each delegate to cross out the four ideas they liked least. Then we got each delegate to choose the idea they liked the most. Once everyone in the group had decided on their own preferred way of taking their key idea to the target customer market we got each member of the group to pitch why their proposed way forward should be adopted, storyboarded and produced by the whole of the group. Sprinters then decided which one of all the proposals to prototype. We asked the decider to decide if the group couldn't reach consensus!

Once the Sprint group had agreed on one proposal to put the "how might we" into practice then delegates were ready to storyboard. This time we got them to draw eight squares on a flip chart and fill them in as a storyboard...like a comic strip if you prefer. This provided a blueprint for the prototype that they would develop. As facilitators, we were helping the Sprint crowd to draw out the idea whilst literally drawing it!

The best storyboards that we saw brought out the passion and emotion of the creative experience - purely from the storyboard. They could show a visitor's emotions as they navigated around a museum. For example, the Memorial Luiz Gonzaga in Recife evoked a journey for us with its narrative of the life of one of the great Brazilian musicians and of the popular culture of North East Brazil. If you were storyboarding its offer to the customer then you could "walk" us through the feelings of moving from exhibit to exhibit. An alternative way of storyboarding could be to represent the different facets of a product or local projects. However, quite simple storyboards led to powerful prototypes (figure 3).

\section{Prototyping}

The second stage of day 3 was building out the storyboard so the Sprinters had a prototype creative economy product or service. Naïve or sophisticated, it simply needed to be good enough to convey the essence of the idea so that we can judge whether it is a viable idea to take forward as part of Sprinters" "offer".

We get and got sprinters to use whatever materials were in the room without insisting on the perfect resource, to avoid spending more time than we would want to produce the "perfect" product. We wanted to avoid the trap of "perfection is the enemy of innovation".

We had a mobile phone "app" from Alagoas that didn't even require tech - it was built of paper and card! However, we did let Sprinters use laptops and cell phones to at this stage to downloading apps and 
software, although some built apps simulated from Power Point or Keynote.

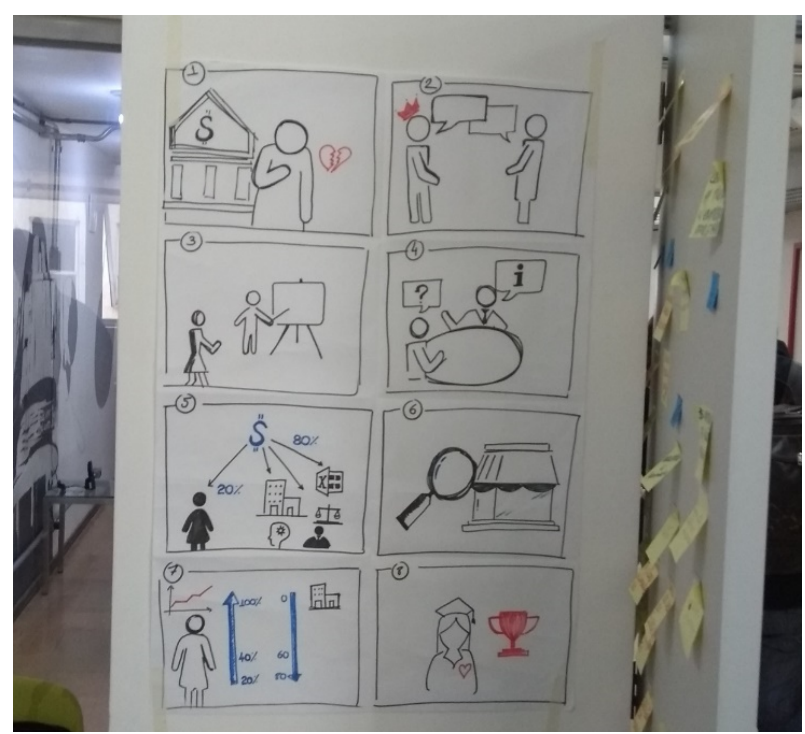

Fig. 3. Storyboarding from Belo Horizonte Sprint delegates

Some made complete films...including occasionally with their lunch and a stray Business Model Canvas (Figure 4).

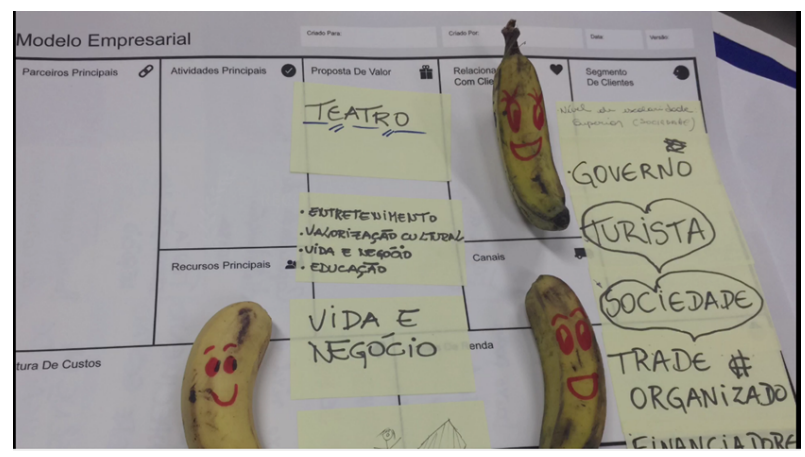

Fig. 4. Alagoas' delegates lunch rapid prototyping.

Sprinters had to present their prototype to us. They already knew what their ideas were or at least thought that they did, however this task ensured everyone was on the same page. They might have instinctively known at this stage whether the prototype is viable to develop further. However, we asked the delegates to also review whether the prototype met the 3 key success factors that they set out on the first day.

When they'd done this we tasked them to plan next steps! Each delegate wrote down how they were going to implement the learning from the Sprint as a "SMART" action plan to implement the prototype.

Where there had been a group of different creative entrepreneurs, the next steps were shaped by how far they had produced a prototype that was relevant to all of them and/or inspirational to all of them. Nevertheless, they still had a process to reshape the offer of the creative entrepreneurs that they worked with and for them to brainstorm new prototypes themselves.
Post Sprint the SMART action plan included ensuring that the prototype was tested with its potential market before being brought to market.

\section{Conclusion}

Two of us ran each Sprint although it could have been facilitated by only one and we have done this going forward. We were an experienced Sprinter and a novice even a slight sceptic!

The process of rapid prototyping and achieving it through drawing as part of a Sprint achieved all our project objectives to facilitate the Brasilian creative economy. The feedback from the pilot sessions was phenomenally good and the Sprint methodology is now being rolled out through SEBRAE [17].

We started wedded to the precise Sprint methodology [16] and ended disrupting a disruptive methodology! However, this was in one country and one continent and we are now looking to inform and develop our methodology with colleagues from Ivano-Frankivsk National Technical University of Oil and Gas. In essence how far is the methodology transferable... early results from Ukraine are promising.

\section{References}

1. T. Okpara, The value of creativity and innovation in entrepreneurship. Journal of Asia Entrepreneurship and Sustainability III(2), 3 (2007)

2. H. van der Pol, Key role of cultural and creative industries in the economy, https://www.oecd.org/site/worldforum06/38703999. pdf. Accessed 7 Mar 2019.

3. I.V. Skavronska, Creative Industries in Ukraine: Analysis and Prospects of the Development (2017), https://www.researchgate.net/publication/31909179 3_Creative_Industries_in_Ukraine_Analysis_and_Pr ospects_of the_Development. Accessed 4 Mar 2019

4. The Creative Economy: Key Concepts and Literature Review Highlights (2013, edited by the Policy Research Group), http://prinnovationhub.com/wpcontent/uploads/2018/08/creative-economysynthesis_201305.pdf. Accessed 7 Mar 2019

5. A. Belyh, Why Creativity is So Crucial For Entrepreneurs? (2015),

https://www.cleverism.com/why-creativity-is-socrucial-for-entrepreneurs/. Accessed 7 Mar 2019

6. B. Marr, What is Industry 4.0? Here's A Super Easy Explanation For Anyone (Forbes, 2018), https://www.forbes.com/sites/bernardmarr/2018/09/ 02/what-is-industry-4-0-heres-a-super-easyexplanation-for-anyone. Accessed 7 Mar 2020

7. E. Ries, The Lean Startup: How Today's Entrepreneurs Use Continuous Innovation to Create Radically Successful Businesses (Penguin, Harmondsworth, 2009)

8. W. Gibson, Neuromancer (Ace, New York, 1984) 
9. 8 pravyl kreatyvnoho predprynymatelia (2016), http://www.startup.org.ua/2016/09/blogpost_10.html. Accessed 4 Mar 2019

10. K. Holubchak, Y. Chuchuk, T. Savchuk, I. Negrych, The phenomenon of creative economy in Ukraine and defining its place in the architectural space (2019), https://www.atlantispress.com/proceedings/mdsmes-19/125919192. Accessed 7 Mar 2019

11. British Council, About (2019), https://creativeconomy.britishcouncil.org/about/. Accessed 1 Mar 2019

12. British Council Brazil (2019), https://creativeconomy.britishcouncil.org/places/bra zil. Accessed $11 \mathrm{Feb} 2019$

13. SEBRAE, Economia Criativa. Available at: http://www.sebrae.com.br/sites/PortalSebrae/segme ntos/economia_criativa. Accessed 1 Mar 2019

14. UNESCO, Brasilia (2019), https://en.unesco.org/fieldoffice/brasilia. Accessed 1 Mar 2019

15. R. Tomlins, Social Value Today (HouseMark, Coventry, 2015)

16. J. Knapp, J. Zeratsky, B. Kowitz, Sprint: how to solve big problems and test new ideas in just five days (Simon and Schuster, New York, 2016)

17. R. Tomlins, H. Cuthill, A. Richards, Sprinting the creative economy (British Council Brasil, São Paulo, 2018) 